\title{
Strong silica-nanocellulose anisotropic composite foams combine low thermal conductivity and low moisture uptake
}

\author{
Pierre Munier • Varvara Apostolopoulou-Kalkavoura • Michael Persson • \\ Lennart Bergström
}

Received: 5 October 2019/ Accepted: 3 December 2019/Published online: 12 December 2019

(C) The Author(s) 2019

\begin{abstract}
We report the fabrication of anisotropic lightweight composite foams based on commercial colloidal silica particles and TEMPO-oxidized cellulose nanofibrils (TOCNF). The unidirectional icetemplating of silica-TOCNF dispersions resulted in anisotropic foams with columnar porous structures in which the inorganic and organic components were homogeneously distributed. The facile addition of silica particles yielded a significant enhancement in mechanical strength, compared to TOCNF-only foams, and a 3.5-fold increase in toughness at a density of $20 \mathrm{~kg} \mathrm{~m}^{-3}$. The shape of the silica particles had a large effect on the mechanical properties; anisotropic silica particles were found to strengthen the foams more efficiently than spherical particles. The water uptake of the foams and the axial thermal conductivity in humid air were reduced by the addition of silica. The composite foams were super-insulating at dry conditions at room temperature, with a radial
\end{abstract}

Electronic supplementary material The online version of this article (https://doi.org/10.1007/s10570-019-02912-0) contains supplementary material, which is available to authorized users.

P. Munier · V. Apostolopoulou-Kalkavoura ·

L. Bergström $(\square)$

Department of Materials and Environmental Chemistry,

Stockholm University, Stockholm, Sweden

e-mail: lennart.bergstrom@mmk.su.se

M. Persson

Nouryon, Performance Chemicals, Bohus, Sweden thermal conductivity value as low as $24 \mathrm{~mW} \mathrm{~m}^{-1}$ $\mathrm{K}^{-1}$, and remained lower than $35 \mathrm{~mW} \mathrm{~m}^{-1} \mathrm{~K}^{-1}$ up to $80 \%$ relative humidity. The combination of high strength, low thermal conductivity and manageable moisture sensitivity suggests that silica-TOCNF composite foams could be an attractive alternative to the oil-based thermal insulating materials.

Keywords Nanocellulose $\cdot$ Silica particles $\cdot$ Foams · Mechanical reinforcement - Moisture uptake ·

Thermal insulation

\section{Introduction}

Biopolymers have recently emerged as a potentially viable alternative to oil-based thermal insulators (Zhao et al. 2018), e.g. expanded polystyrene (EPS) (Horvath 1994; Jelle 2011), a widely used material for domestic insulation. Bio-based thermally insulating foams and aerogels have been produced using e.g. pectins (Zhao et al. 2015a; Groult and Budtova 2018), cellulose fibers (Nguyen et al. 2014) and cellulose nanomaterials or CNMs (ISO/TS 20,477 2017) (Lavoine and Bergström 2017). CNMs display a high strength and low thermal conductivity in combination with a versatile surface chemistry (Kontturi et al. 2018) and are now approaching the state of mass production (Rajinipriya et al. 2018). 
Thermally insulating and strong CNM-based materials with direction-dependent heat transport properties can be produced using processing routes that take advantage of the intrinsically anisotropic properties of nanocellulose (Dri et al. 2014). An example of such routes is directional ice-templating, also called freezecasting (Deville 2018). Initially designed for the processing of ceramics, directional ice-templating has been increasingly utilized for the elaboration of biomaterials with specific architectures (Deville 2010; Wegst et al. 2010). By applying different directional cooling gradients to liquid dispersions, the growth direction of ice crystals can be controlled. The sublimation of the ice crystals then not only leads to various anisotropic porous structures, but within these structures anisotropic particles can self-assemble in unique ways (Bouville et al. 2014). In a previous work, TEMPO-oxidized cellulose nanofibril (TOCNF) dispersions were used in such a fashion to generate foams with aligned columnar pores and aligned nanofibrils (Munier et al. 2016). Ice-templated anisotropic nanocellulose-based foams were shown to display very low thermal conductivity (down to $18 \mathrm{~mW} \mathrm{~m}^{-1}$ $\mathrm{K}^{-1}$ ) perpendicularly to the fibrils' and pores' axes (Wicklein et al. 2014). However, nanocellulose-based foams are moisture sensitive (Saito et al. 2007; Apostolopoulou-Kalkavoura et al. 2018; Guo et al. 2018a; Illera et al. 2018), resulting in low strength and increased thermal conductivity at high relative humidity $(\mathrm{RH})$ values.

Inorganic nanoparticles are commonly added to impart additional or improved properties to nanocellulose-based composite materials. Mixing nanocellulose with, for example, particles of clay (Donius et al. 2014; Wicklein et al. 2014), silica (Chu et al. 2017; Zuo et al. 2019), hydroxyapatite (Guo et al. 2018b), metal-organic frameworks (Zhu et al. 2016) or metal oxides (Korhonen et al. 2011) resulted in anisotropic composite foams with enhanced mechanical strength, fire retardancy and thermal resistance. Moreover, TOCNF-graphene oxide-sepiolite clay-boric acid foams were shown to display extraordinarily low radial thermal conductivity (Wicklein et al. 2014); similar values were also obtained with cellulose nanofibrils and silica using a different approach (Zhao et al. 2015b).

Herein, anisotropic silica-nanocellulose composite foams were produced by ice-templating aqueous dispersions of TEMPO-oxidized cellulose nanofibrils and isotropic and necklace-like commercially available colloidal silica nanoparticles. The mechanical properties, thermal conductivity and moisture uptake were determined as a function of composition and particle type, and compared to pure TOCNF foams. The influence of relative humidity (RH) on the thermal conductivity was assessed in detail.

\section{Materials and methods}

\section{Materials}

Never-dried sulfite softwood cellulose pulp (Domsjö dissolving Plus) was provided by Domsjö Fabriker AB (Aditya Birla Domsjö, Sweden) and washed with a $\mathrm{pH}=2$ hydrochloric acid solution. Sodium hypochlorite (NaClO, Merck), 2,2,6,6-tetramethyl-1piperidinyloxy free radical (TEMPO, Sigma-Aldrich), sodium hydroxide $(\mathrm{NaOH}, \mathrm{VWR}$ International) and sodium bromide ( $\mathrm{NaBr}$, Sigma-Aldrich) were used as received. Aqueous dispersions of colloidal silica, Levasil@ CS30-236 ("isotropic silica”) and Levasil® CS15-175 ("anisotropic silica") were kindly provided by Nouryon Performance Chemicals (Bohus, Sweden) and diluted with deionized water to the desired concentrations.

TEMPO-oxidized cellulose nanofibrils (TOCNF) were prepared as previously reported using a TEMPO/ $\mathrm{NaBr} / \mathrm{NaClO}$ system with $10 \mathrm{mmol}$ of $\mathrm{NaClO}$ per gram of cellulose (Saito and Isogai 2004). The TEMPO-mediated oxidation was performed on $40 \mathrm{~g}$ of never-dried sulphite softwood cellulose pulp at $\mathrm{pH}=10$ for $200 \mathrm{~min}$. The oxidized pulp obtained was washed thoroughly with deionized water to remove any excess of reagents. The TOCNF were obtained by grinding using a supermasscolloider grinder (Model MKZA10-15 J, Masuko Sangyo Co., Ltd, Japan) equipped with non-porous grinding stones containing silicon carbide (Disk model MKE). The oxidized pulp was diluted to a concentration of $0.5 \mathrm{wt} \%$ and passed through the supermasscolloider 4 to 5 times, using a gap clearance of $-50 \mu \mathrm{m}$ at a rotating speed of $25 \mathrm{~Hz}$.

Particle and suspension characterization

Atomic force microscopy (AFM, dimension 3100, Bruker, USA) operated in tapping mode was used to image the TOCNF and colloidal silica particles. A 
droplet of $0.005 \mathrm{wt} \%$ dispersion was deposited onto freshly cleaved mica substrate and dried under ambient conditions. The average diameter of TOCNF was estimated from the manual measurement of 50 particles (Gordeyeva et al. 2016).

The surface charge of the TOCNF was estimated by conductometric titration of carboxylic groups $\left(\mathrm{COO}^{-}\right)$ with sodium hydroxide used as a titrant. The obtained

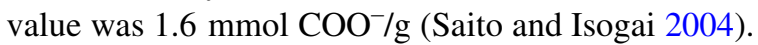

The viscosity of TOCNF and silica-TOCNF dispersions was assessed via rheological measurements, performed at $25^{\circ} \mathrm{C}$ using a Physica MCR 301 rheometer (Anton Paar) equipped with a smooth concentric cylinder bob and cup geometry (CC27/ T200/SS). The studied dispersions were mixed for several hours using magnetic stirring. Steady-shear measurements were performed from 0.1 to $1000 \mathrm{~s}^{-1}$ and vice versa.

Zeta potential and dynamic light scattering (DLS) measurements were performed using a Zetasizer Nano ZS (Malvern Instruments Ltd., UK), equipped with a $530 \mathrm{~nm}$ laser and backscatter detector (at an angle of $173^{\circ}$ ). The measurements were performed on TOCNF, silica and silica-TOCNF dispersions at a total concentration of $0.005 \mathrm{wt} \%$, mixed for several hours with a magnetic stirrer and, for some of them, sonicated for 10 min (USC500TH, VWR International). After dilution with deionized water, the $\mathrm{pH}$ of the dispersions was adjusted using aqueous solutions of hydrochloric acid and/or sodium hydroxide. For each sample, the final results were averaged from the data obtained from 3 measurements of 150 to 200 runs each.

Preparation and characterization of anisotropic silica-TOCNF composite foams

The anisotropic TOCNF and silica-TOCNF foams were prepared by unidirectional ice-templating of aqueous dispersions diluted with deionized water and magnetically stirred for several hours. Cylindrical teflon molds of two different sizes (diameter $\mathrm{x}$ length $=2 \times 2 \mathrm{~cm}$ and $4 \times 4.5 \mathrm{~cm})$, closed by a bottom copper plate (Ojuva et al. 2013), were filled in with the dispersions and directly put in contact with dry ice. With the present setup, the freezing rate of the dispersions was evaluated to approximately $3 \mathrm{~K} / \mathrm{min}$. The final dry foams were obtained by ice sublimation at 0.024 mbar and room temperature for 4 days using a freeze-dryer (Christ Alpha 1-2LDplus, Germany).
The apparent density of the foams was calculated from the mass and the volume of the foams, kept for 3 days at room conditions (approx. $22{ }^{\circ} \mathrm{C}$ and $50 \%$ $\mathrm{RH})$.

The porosity of the foams was determined from the skeletal density of bulk cellulose silica materials (values obtained from the literature) and the apparent density of the foams.

Nitrogen sorption measurements were performed using an ASAP 2020 (Micromeritics Instrument Corporation, Nocross, GA, USA). The BrunauerEmmett-Teller (BET) model (Gelb and Gubbinst 1998) was used to estimate the surface area of the foams. The foams were degassed at $80{ }^{\circ} \mathrm{C}$ for at least 840 min. prior to the measurements. The BarrettJoyner-Halenda (BJH) model (Baisheng et al. 2015) was used to estimate the cumulative volume of pores (for diameters between 17 and $3000 \AA$ ) and the average pore diameter in the foam walls.

The porosity of the foam walls was determined by taking into account the apparent and skeletal densities of the foams as well as the results obtained by nitrogen sorption measurements.

Scanning electron microscopy (SEM) images of the foam structures were taken using a HITACHI TM3000 (Germany) using an accelerating voltage of $5 \mathrm{kV}$ at a magnification of $\times 100-200$. The same instrument was used for Energy-Dispersive X-ray Spectroscopy (EDS) analysis of the foams. High-resolution SEM images of the foam walls were taken using a JEOL JSM-7401F (USA) using a working distance of $6 \mathrm{~mm}$ and an accelerating voltage of $1 \mathrm{kV}$ at a magnification of $\times 5000-45,000$. Pieces of foams were mounted on metallic plates previously covered by a carbon or copper tape. A thin layer of gold was coated on the foam pieces before analysis.

$\mathrm{X}$-ray diffraction (Bruker D8 Venture) was used to characterize the degree of alignment (Hermans' orientation parameter) of the TOCNF in the freeze-cast foams. The beam source was molybdenum (Mo) K $\alpha 1$ $(\lambda=0.71 \mathrm{~nm})$ and the detector was a Shutterless Photon 100 CMOS. A $10^{\circ}$ phi scan was performed with an exposure time of $15 \mathrm{~s}$ per degree and a sampleto-detector distance of $100 \mathrm{~mm}$.

To determine the Hermans' orientation parameter, the foams were compressed in the radial direction and 2D patterns were recorded. The Hermans' orientation parameter, $\mathrm{f}_{\mathrm{H}}$, quantitatively describes the alignment of the TOCNF relatively to the ice growth direction. $\mathrm{f}_{\mathrm{H}}$ 
was obtained by azimuthal integration of the (200) peak of cellulose $\left(\theta=11.4^{\circ}\right)$ and Eqs. 1 and 2.

$f_{H}=\frac{3<\cos ^{2} \varphi>-1}{2}$

$$
<\cos ^{2} \varphi>=\frac{\sum_{0}^{\pi / 2} I(\varphi) \sin \varphi \cos ^{2} \varphi}{\sum_{0}^{\pi / 2} I(\varphi) \sin \varphi}
$$

where $\varphi$ represents a theoretical angle between a nanofibril main direction and the ice crystal growth direction. This angle can be identified as the azimuthal angle on the $2 \mathrm{D}$ pattern (Fig. $1 \mathrm{c})$. $\mathrm{I}(\varphi)$ represents the intensity at a certain $\varphi$ angle (Sehaqui et al. 2012).

The compressive behavior of the foams in the axial direction was evaluated using an Instron 5944 mechanical testing instrument (Instron, U.S.A.) equipped with a $100 \mathrm{~N}$ load cell. The foams were conditioned for at least $24 \mathrm{~h}$ at $23{ }^{\circ} \mathrm{C}$ and $50 \% \mathrm{RH}$ prior to the measurements. The mechanical testing was conducted at $23{ }^{\circ} \mathrm{C}$ and $50 \% \mathrm{RH}$ at a compression rate of $2 \mathrm{~mm} \mathrm{~min}^{-1}$. The compressive Young's modulus was determined from the slope of the initial linear region of the stress-strain curve, and the energy absorbed by the foam (i.e., toughness) was evaluated from the area under the stress-strain curve up to $70 \%$ strain (Sehaqui et al. 2011). The average value and standard deviations of measurements on five foam specimens are reported.

Differential Scanning Calorimetry (DSC) experiments were conducted to estimate the dry specific heat capacity of the used materials (Mettler Toledo DSC1 STARe System). The foams or initial dispersions were dried for $24 \mathrm{~h}$ at $105{ }^{\circ} \mathrm{C}$ in an oven prior to the measurements. At least $10 \mathrm{mg}$ of material were sealed in aluminum crucibles. A $10 \mathrm{~K} / \mathrm{min}$ cooling and heating rate were selected for every measurement. The dry specific heat capacity of the materials was determined between -20 and $50{ }^{\circ} \mathrm{C}$ under nitrogen atmosphere.

The water vapor sorption of the silica-TOCNF foams under controlled $\mathrm{RH}$ and temperature was determined by measuring the mass change using a high-precision balance (BP 210 S, Sartorius, Germany) placed inside a humidity chamber (Climacell (a)

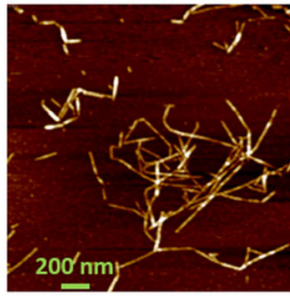

TOCNF

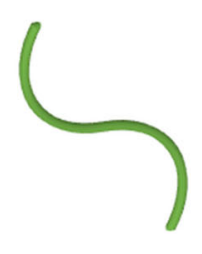

AND (b)

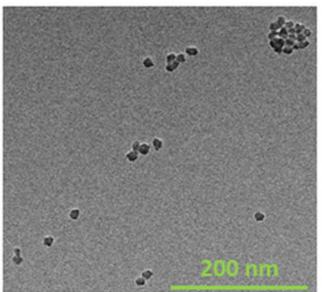

Isotropic silica

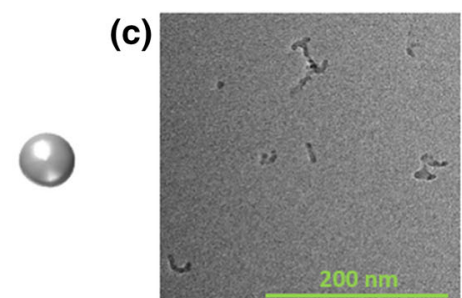

Anisotropic silica

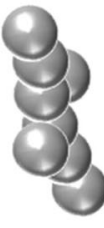

OR

(d)

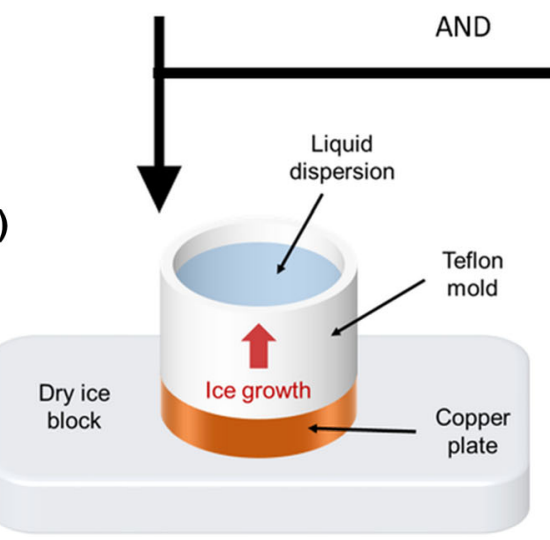

Fig. 1 Preparation of silica-TOCNF composite foams by directional ice-templating. a Atomic force microscopy (AFM) micrograph illustrating the structure of TOCNF. Transmission electron microscopy (TEM) images of; $\mathbf{b}$ isotropic silica and; c anisotropic silica. All scale bars correspond to a length of
$200 \mathrm{~nm}$. d Schematic of freeze-casting of composite dispersions. e Photograph of a freeze-cast and freeze-dried composite foam, with arrows indicating the radial $[\mathrm{R}]$ and axial $[\mathrm{A}]$ directions. The scale bar corresponds to a length of $1 \mathrm{~cm}$ 
Evo, MMM group). Prior to the measurements, the foams were dried at $40{ }^{\circ} \mathrm{C}$ and $20 \% \mathrm{RH}$. The moisture content $\left(\mathrm{H}_{2} \mathrm{O}_{\mathrm{w}}\right)$ as a function of $\mathrm{RH}(20,35,50,65$ and $80 \%$ ) was assessed at $22{ }^{\circ} \mathrm{C}$. Each measurement lasted $6 \mathrm{~h}$ to ensure that steady state was reached, and the foam mass was measured every $30 \mathrm{~s}$.

The thermal conductivity of the foams was measured using the TPS $2500 \mathrm{~S}$ Hot Disk Thermal Constants Analyzer in anisotropic mode (Gustafsson 1991). The TPS sensor (6.4 $\mathrm{mm}$ in radius) was placed between two identical pieces of foams (diameter: $4.1 \pm 0.1 \mathrm{~cm}$; height: $2.4 \pm 0.2 \mathrm{~cm}$ ). The good thermal contact between the sensor and the foams was ensured by putting a small weight onto the samples. The heating power was $20 \mathrm{~mW}$ and the measurement time was $10 \mathrm{~s}$ for each thermal conductivity measurement. The foams were enclosed in the customized cell, allowing the RH to be controlled (between 2 and 80\%) using a P2 Cellkraft humidifier (Ocklind 2016). Five independent measurements were performed with 15 min interval time for each $\mathrm{RH}$ on two pairs of foam specimens. The thermal conductivity values of the anisotropic foams at different $\mathrm{RH}$ were calculated using the specific heat capacity $(\mathrm{Cp})$ and density of the foams as input. The dry $\mathrm{Cp}$ of the foams $\left(\mathrm{Cp}_{\mathrm{dry}}\right)$ was measured using DSC and the wet Cp $\left(\mathrm{Cp}_{\text {wet }}\right)$ was calculated using the rule of mixtures taking into consideration the water uptake of the foams at each RH (Eq. 3):

$C_{P_{w e t}}=\left(1-\mathrm{H}_{2} \mathrm{O}_{w}\right) \times C_{P_{d r y}}+C_{P_{\mathrm{H}_{2} \mathrm{O}}} \times \mathrm{H}_{2} \mathrm{O}_{w}$

where $\mathrm{H}_{2} \mathrm{O}_{\mathrm{w}}$ is the water content by mass in $\mathrm{wt} \%$, $\mathrm{Cp}_{\mathrm{dry}}$ is the dry specific heat capacity of the foams measured in the DSC in $\mathrm{J} \mathrm{K}^{-1} \mathrm{~kg}^{-1}$ and $\mathrm{Cp}_{\mathrm{H} 2 \mathrm{O}}$ is the specific heat capacity of water in $\mathrm{J} \mathrm{K}^{-1} \mathrm{~kg}^{-1}$. Accordingly, for the wet density, the wet mass of the foams $\left(\mathrm{m}_{\text {wet }}\right)$ was calculated using Eq. 4:

$m_{\text {wet }}=m_{d r y}+m_{\mathrm{H}_{2} \mathrm{O}}$

where $m_{\text {dry }}$ is the dry mass of the foams in $\mathrm{kg}$ and $\mathrm{m}_{\mathrm{H} 2 \mathrm{O}}$ is the mass of water in $\mathrm{kg}$.

The foams' shrinkage during thermal conductivity experiments was taken into consideration for assessing the volume change of the foams during the water uptake measurements. The foams were mounted on the customized cell and the volume of the foams was measured after each humidity cycle with a caliper. Taking into consideration the volume shrinkage and the moisture content, the wet density of the foams was calculated and used for the calculations of the thermal conductivity in Hot Disk.

\section{Results and discussion}

Freeze-cast silica-TOCNF foams

We have produced silica-TOCNF anisotropic foams by directional ice-templating of aqueous dispersions of cellulose nanofibrils carboxylated via TEMPOmediated oxidation (TOCNF) (Fig. 1a), and two different types of industrially produced colloidal silica particles. The "isotropic silica" (Fig. 1b), consists of spherical particles with an average diameter of $16 \mathrm{~nm}$. The "anisotropic silica" (Fig. 1c), consists of anisotropic necklace-like particles with minor branching obtained by the fusing of several isotropic particles. The directional ice-templating, or freeze-casting, was performed by exposing the aqueous dispersions to dry ice on one side only through a copper plate (see Fig. 1d). The ice was then removed by freeze-drying, resulting in lightweight foams (Fig. 1e).

The amount of TOCNF in the initial dispersions and thus in the foams was kept constant at $0.4 \mathrm{wt} \%$, whereas the amount of colloidal silica was varied. Foams made solely from a $0.4 \mathrm{wt} \%$ TOCNF dispersion at $\mathrm{pH} 7$ were used as a reference and are abbreviated with " $\mathrm{T}$ ". Foams made from composite dispersions at $\mathrm{pH} 10$ with isotropic or anisotropic silica were respectively abbreviated with "I" or "A", followed by a number indicating the silica-TOCNF weight ratio. For example, a foam made from a dispersion containing $0.4 \mathrm{wt} \%$ TOCNF and $0.8 \mathrm{wt} \%$ isotropic silica will be named $\mathrm{I} 2$.

The homogeneity and colloidal state of the dispersions were assessed by zeta potential and Dynamic Light Scattering (DLS) measurements. Table S1 shows that the single component and composite dispersions displayed average zeta potential values between -59 and $-45 \mathrm{mV}$, which suggests that the electrostatic repulsion between the negatively charged particles should be of sufficient magnitude to ensure a good colloidal stability (Park et al. 2015). DLS measurements were conducted on single component (Fig. S1) and composite dispersions (Fig. S2), with and without sonication. The results showed that the particle size distributions of composite dispersions 
prepared with magnetic stirring were comparable to those of sonicated mixtures, as well as to the single component dispersions, which supports that the mixtures used during freeze-casting, simply magnetically stirred, are well dispersed.

The obtained freeze-cast foams possess an anisotropic columnar macroporous structure, as schematized in Fig. 2a, in which two characteristic directions can be defined (see Fig. 1e). The cylindrical pores are oriented in the axial direction, which is parallel to the direction of the ice front's growth during freezecasting. The cellulose nanofibrils are also expected to be oriented in the axial direction, as shown in previous work on freeze-cast nanocellulose foams (Munier et al. 2016). In order to verify the preservation of TOCNF alignment along the freezing direction in the composite foams, X-Ray Diffraction measurements were performed (Fig. S3). All tested foams displayed similar 2D-patterns with two azimuthal intensity peaks. The obtained Hermans' orientation parameter values showed a slight decrease in alignment upon addition of silica. Nevertheless, all average values ranged between 0.19 and 0.26 , which corresponds to a moderate alignment (Kriechbaum et al. 2018). It can thus be concluded that the addition of silica particles did not significantly disrupt the ice-templating-induced alignment of TOCNF.

Scanning Electron Microscopy (SEM) images show very similar macroporous structures for all silica-TOCNF and TOCNF foams prepared in this study. Comparing the structure of an A2 foam in the radial (Fig. 2b) and axial (Fig. 2c) directions confirms that the columnar macropores, with diameters in the range of tens of micrometers, are oriented along the freezing direction. SEM images of other foams studied herein display similar macropore diameters and anisotropic pore structures (Fig. S4). Figure 2d shows that the foam walls of the composite foams were very thin, estimated to vary between 50 and $500 \mathrm{~nm}$. Energy-Dispersion X-ray spectroscopy (EDS) analysis on an A2 foam (Figure 2e-f) shows that the (a)

(b)
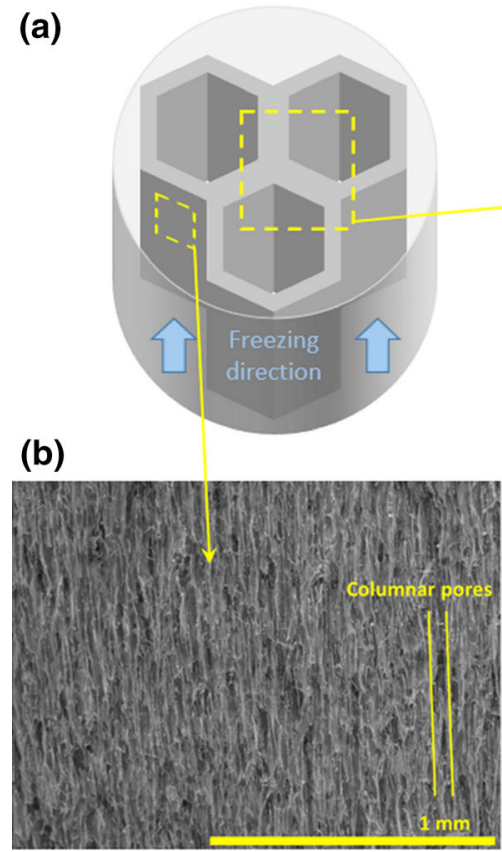

(c)

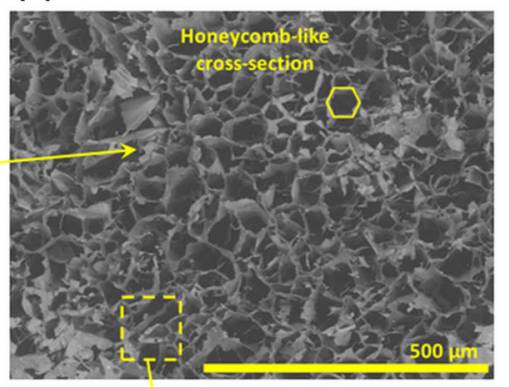

(d)

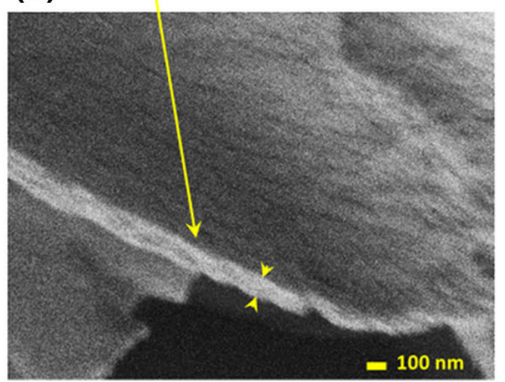

(e)

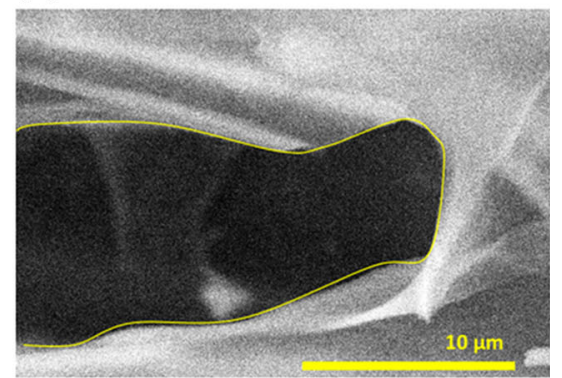

(f)

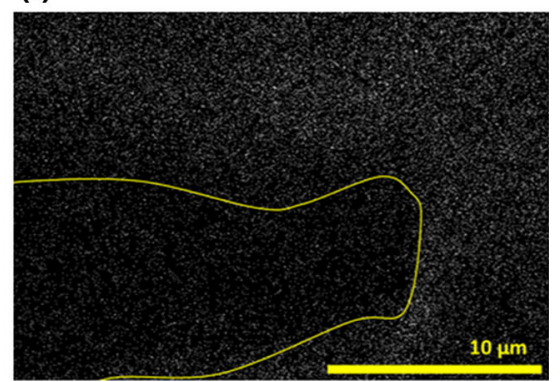

Fig. 2 Columnar porous structure of ice-templated silicaTOCNF composite foams. a Schematic representation of the columnar porous structure of the composite foams produced by freeze-casting. Representative images of the porous structure of an A2 foam, observed by scanning electron microscopy (SEM); b Axial view, scale bar is equal to $1 \mathrm{~mm}$; c Radial view, scale bar is equal to $500 \mu \mathrm{m}$; d High-magnification SEM image of a single A2 foam wall, scale bar is equal to $100 \mathrm{~nm}$. Energy dispersive X-ray spectroscopy (EDS) analysis of an A2 foam wall; e SEM image of the section of the foam wall used for the analysis; f Elemental mapping for silicon (represented by white dots). The scale bars are equal to $10 \mu \mathrm{m}$. The yellow line is a guide for the eye 
distribution of silica particles within the foam is homogeneous.

Table 1 shows that the surface area of composite foams increased and the average pore diameter in the pore walls decreased with increasing silica content. Furthermore, the total pore volume in the pore walls, for pore diameters between 17 and $3000 \AA$, was drastically increased with the addition of silica (note that the pore volume refers to the porosity within the foam walls and not to the macroporosity observed in Fig. 2b). These results indicate that the packing of aligned TOCNF during freeze-casting is becoming less ordered from the presence of silica particles.

\section{Effect of composition on mechanical properties}

The compressive behavior of isotropic silica-TOCNF composite foams with silica-TOCNF weight ratios ranging from 1 to 5 displays three distinct regions (Fig. 3a): the linear-elastic deformation region at low strains, a plateau corresponding to the elastic then plastic buckling of the foam walls at intermediate strains, and finally the densification region at high strains (Gibson and Ashby 1999). The toughness of the I foams (Fig. 3b, black circles), which was calculated by integrating the stress-strain curves between 0 and $70 \%$ strain, as well as the elastic Young's modulus (Fig. 3c, black circles), which was obtained from the linear elastic deformation region, increased with increasing density and silica content in the foams.
Increasing the silica content from 0 to $83.5 \mathrm{wt} \%$ in the dry foams (which corresponds to foams $\mathrm{T}$ and I5) resulted in a 3.5-fold increase of the toughness while the increase in Young's modulus was ninefold. In fact, Fig. 3b, c show that the increase in toughness with increasing density appeared to be linear, while the evolution of Young's modulus seemed to follow a parabolic relation. Hence, the increase in stiffness with increasing silica content was always larger than the increase in toughness, which resulted in more brittle composite foams at high silica contents. Indeed, compression tests on the composite foams with the highest silica content, I4 and I5, revealed the failure and detachment of millimeter-sized pieces from the main body of the highly compressed foams. Table 2 shows that the specific toughness, i.e. toughness divided by density (Tripathi et al. 2019), was slightly lower for all the composite foams with isotropic silica compared to the TOCNF foams. Hence, the strengthening of the foams upon loading the TOCNF network with isotropic silica particles was not sufficient to compensate the increase in density. Nevertheless, the I2 foams could sustain a high compression without fracture and displayed the highest specific toughness. From here on, the study will be focused on composite foams with a silica-TOCNF weight ratio of 2 .

The A2 foams (see a representative stress-strain curve in Fig. S5) displayed a much higher Young's modulus and toughness than the I2 foams (Fig. 3b, c). In fact, the average Young's modulus for A2 foams $(299 \mathrm{kPa})$ was comparable with that of I4 foams

Table 1 Summary of the information obtained during the nitrogen sorption experiments conducted on TOCNF and silica-TOCNF foams

\begin{tabular}{llll}
\hline Sample & $\begin{array}{l}\text { BET surface area } \\
\left(\mathrm{m}^{2} \mathrm{~g}^{-1}\right)\end{array}$ & $\begin{array}{l}\text { BJH adsorption average pore diameter } \\
(\mathrm{nm})\end{array}$ & $\begin{array}{l}\text { BJH adsorption cumulative volume of pores } \\
\left(\mathrm{cm}^{3} \mathrm{~kg}^{-1}\right)\end{array}$ \\
\hline $\mathrm{T}$ & 11.5 & 10.4 & 27 \\
$\mathrm{I} 1$ & 52.8 & 4.8 & 63 \\
$\mathrm{I} 2$ & 94.0 & 4.4 & 100 \\
$\mathrm{I} 3$ & 127.8 & 4.2 & 138 \\
$\mathrm{I} 4$ & 150.1 & 4.1 & 156 \\
$\mathrm{I} 5$ & 160.7 & 4.2 & 164 \\
$\mathrm{~A} 2$ & 152.6 & 4.3 & 161 \\
\hline
\end{tabular}

The surface area was estimated via the Brunauer-Emmett-Teller (BET) method, while the average pore diameter and cumulative volume of pores were estimated via the Barrett-Joyner-Halenda $(\mathrm{BJH})$ method. For the cumulative volume of pores, only pores with diameters between 17 and $3000 \AA$ were taken into account 
(a)

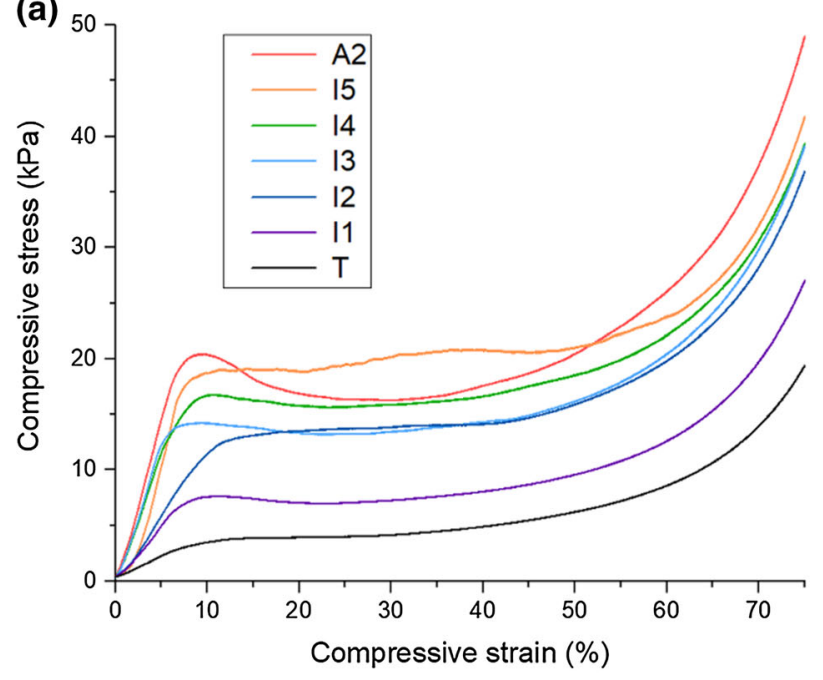

Fig. 3 Mechanical properties of composite silica-TOCNF foams. a Stress-strain curves obtained during mechanical compression tests on silica-TOCNF foams. Evolution of $\mathbf{b}$ the
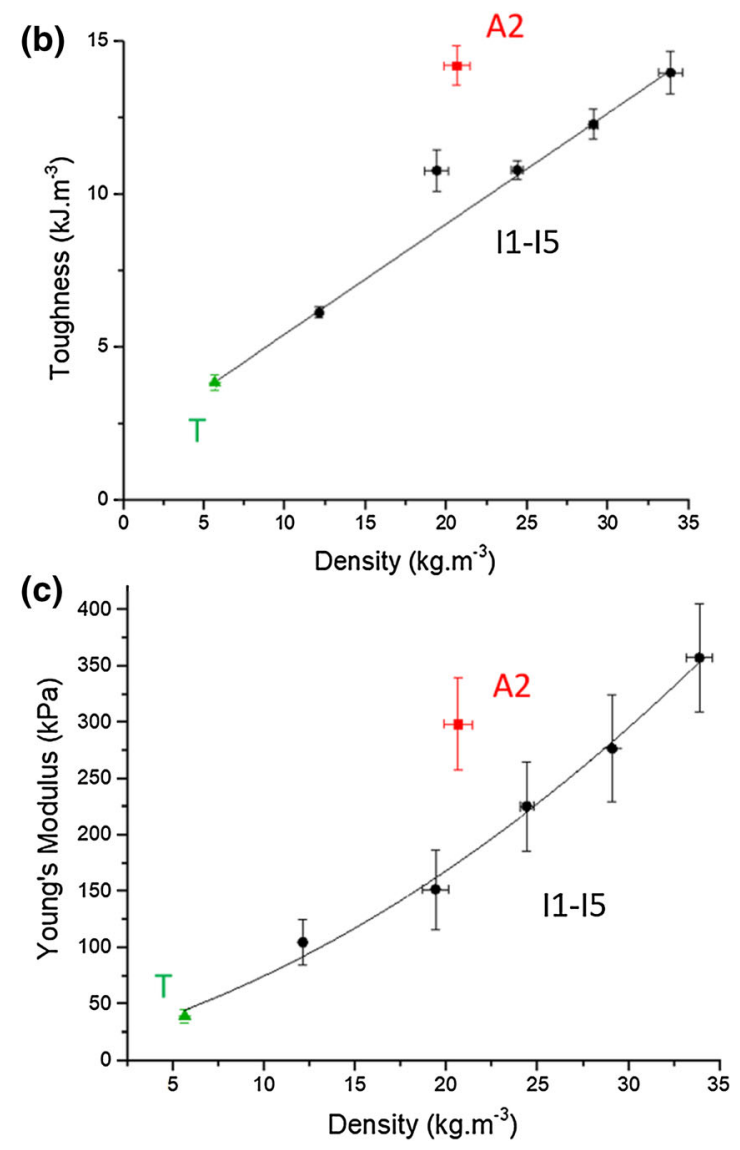

toughness, and $\mathbf{c}$ the Young's modulus, as a function of density, for foams with silica/TOCNF ratios ranging from 1 to 5 , as well as for reference TOCNF foams
Table 2 Toughness and specific toughness obtained from mechanical compression measurements for all tested foams

\begin{tabular}{lccl}
\hline Composition & Toughness $\left(\mathrm{kJ} \mathrm{m}^{-3}\right)$ & Density $\left(\mathrm{kg} \mathrm{m}^{-3}\right)$ & Specific toughness $\left(\mathrm{J} \mathrm{g}^{-1}\right)$ \\
\hline $\mathrm{T}$ & $3.9 \pm 0.2$ & $5.7 \pm 0.1$ & $0.68 \pm 0.05$ \\
$\mathrm{I} 1$ & $6.1 \pm 0.2$ & $12.1 \pm 0.1$ & $0.51 \pm 0.02$ \\
$\mathrm{I} 2$ & $10.8 \pm 0.7$ & $19.4 \pm 0.7$ & $0.56 \pm 0.06$ \\
$\mathrm{I} 3$ & $10.8 \pm 0.3$ & $24.4 \pm 0.4$ & $0.44 \pm 0.02$ \\
$\mathrm{I} 4$ & $12.3 \pm 0.5$ & $29.1 \pm 0.3$ & $0.42 \pm 0.02$ \\
$\mathrm{I} 5$ & $33.9 \pm 0.7$ & $0.41 \pm 0.03$ \\
$\mathrm{~A} 2$ & $14.0 \pm 0.7$ & $20.6 \pm 0.8$ & $0.69 \pm 0.06$ \\
\hline
\end{tabular}

$(277 \mathrm{kPa})$, whereas the average toughness for A2 foams $\left(14.2 \mathrm{~kJ} \mathrm{~m}^{-3}\right)$ was comparable with that of I5 foams $\left(14.0 \mathrm{~kJ} \mathrm{~m}^{-3}\right)$. The average density of the A2 foams $\left(20.6 \pm 0.8 \mathrm{~kg} \mathrm{~m}^{-3}\right)$ was similar to the $\mathrm{I} 2$ foams, which is expected because the silica-TOCNF ratios were identical for the two different foams. Consequently, the specific toughness of the A2 foams $\left(0.69 \mathrm{~J} \mathrm{~g}^{-1}\right)$ was higher than for any $\mathrm{I}$ foam and essentially identical as that of the $T$ foams $\left(0.68 \mathrm{~J} \mathrm{~g}^{-1}\right)$. In short, A2 foams showed a similar toughness as foams with more than double amounts of isotropic silica and a 65\% higher density, thus maintaining the same specific toughness as nonreinforced $\mathrm{T}$ foams. 
A possible explanation for the difference between the two types of silica could be that the shear forces that act on the suspended particles during freezecasting (Hunger et al. 2013) may not only align the TOCNF, but also the anisotropic silica particles. The alignment of the anisotropic silica particles could strengthen the structure in the axial direction. In the next section, the effect of both types of silica particles on the moisture uptake and thermal conductivity will be investigated and compared.

Effect of RH on water uptake and thermal conductivity

The anisotropic thermal conductivity of the freezecast foams, in the radial and axial directions, was measured using the Transient Plane Source (TPS) method in a customized cell where temperature and RH could be controlled. The thermal conductivity measurements were complemented with Differential Scanning Calorimetry (DSC) measurements of the dry specific heat capacity of the foams $\left(\mathrm{Cp}_{\mathrm{dry}}\right)$ (Table $\left.\mathrm{S} 2\right)$ at the temperature of the measurement $\left(22^{\circ} \mathrm{C}\right)$, and the water uptake of the foams $\left(\mathrm{H}_{2} \mathrm{O}_{\mathrm{w}}\right)$ at the $\mathrm{RH}$ of the measurement. Table 3 shows that $\mathrm{H}_{2} \mathrm{O}_{\mathrm{w}}$ is lower in the composite foams compared to the $\mathrm{T}$ foams for $\mathrm{RH}$ between 20 and $80 \%$. The composite I 2 and A2 foams displayed a moisture uptake at $\mathrm{RH}=20 \%$ that was about 3 times lower than the $\mathrm{T}$ foams at $\mathrm{RH}=20 \%$. Hence, the presence of silica particles appeared to limit the water uptake of the highly hydrophilic cellulose nanofibrils. However, the water uptake of the A2 foams increased strongly at high $\mathrm{RH}$, and approached the moisture uptake of the $\mathrm{T}$ foams while

Table 3 Moisture uptake of silica-TOCNF foams

\begin{tabular}{llcc}
\hline RH $(\%)$ & \multicolumn{3}{l}{ Water uptake } \\
\cline { 2 - 4 } & T $(\%)$ & I2 (\%) & A2 (\%) \\
\hline 20 & 10.8 & 4.0 & 4.2 \\
35 & 11.8 & 5.2 & 6.0 \\
50 & 13.0 & 7.1 & 8.8 \\
65 & 14.5 & 9.4 & 13.1 \\
80 & 17.0 & 11.1 & 15.9 \\
\hline
\end{tabular}

Water uptake in percentage $\left(\mathrm{H}_{2} \mathrm{O}_{\mathrm{w}}\right)$ of dry freeze-cast foams, recorded at different $\mathrm{RH}$ the water uptake of the $\mathrm{I} 2$ foams remained low. The higher BET surface area and BJH total pore volume (Table 1) of the A2 foams compared to I2 foams suggests that the higher water uptake of the A2 foams compared to the I 2 foams at high RH may be related to a difference in the physical barrier created by the different silica particles.

Figure 4a shows that the radial thermal conductivity values for the $\mathrm{T}$ foams were lower than that of air $\left(25.7 \mathrm{~mW} \mathrm{~m}^{-1} \mathrm{~K}^{-1}\right)$ at $\mathrm{RH}>20 \%$, but the composite foams also displayed a thermal conductivity lower than that of air for $\mathrm{RH}<35 \%$ (as low as 24 $\mathrm{mW} \mathrm{m}{ }^{-1} \mathrm{~K}^{-1}$ ). At higher $\mathrm{RH}$, the radial thermal conductivity of the composite foams remained lower than $35 \mathrm{~mW} \mathrm{~m}^{-1} \mathrm{~K}^{-1}$, which still is a synonym of relatively good performance in comparison with EPS foams, for example (Horvath 1994).

The very low thermal conductivity of the composite foams at low RH can be related to the substantial increase in the overall surface area and pore volume of the foam walls, together with a decrease in the average pore size, compared to the $\mathrm{T}$ foams. In fact, the thermal conductivity of the foams can be separated in three main contributions, i.e. the conduction in the solid phase, in the gaseous phase present in the columnar macropores and in the gaseous phase present within the wall mesopores (Glicksman 1994). The variations in mesoporosity between the different foams induce variations in the relative weight of these different contributions. The weight of the contribution to the thermal conductivity of the wall mesopores can be estimated by calculating their specific contribution via the mesopore gaseous conduction $\lambda_{\mathrm{g}}{ }^{\text {meso }}$ and comparing it to the macropore gaseous conduction $\lambda_{\mathrm{g}}$ macro (see details in online Appendix). Table 4 shows that there is a clear difference between the gaseous conduction in the mesopores and the macropores of the foams: with much lower values for $\lambda_{\mathrm{g}}{ }^{\text {meso }}$ than for $\lambda_{\mathrm{g}}{ }^{\text {macro }}$ in all foams, it appears that the presence of mesopores is crucial to obtain an overall low thermal conductivity in the material. Table 4 also shows that the $\mathrm{I} 2$ and $\mathrm{A} 2$ foams possess much higher mesopore fractions compared to the $\mathrm{T}$ foams, which could explain why the dry thermal conductivity of composite foams is lower than for $\mathrm{T}$ foams, although the densities of the A2 and I 2 foams are higher than the T foam.

The thermal conductivities of the I2 and A2 foams in the axial direction as a function of $\mathrm{RH}$ (see Fig. S6) varied between 82 and $134 \mathrm{~mW} \mathrm{~m}^{-1} \mathrm{~K}^{-1}$, which is 
(a)

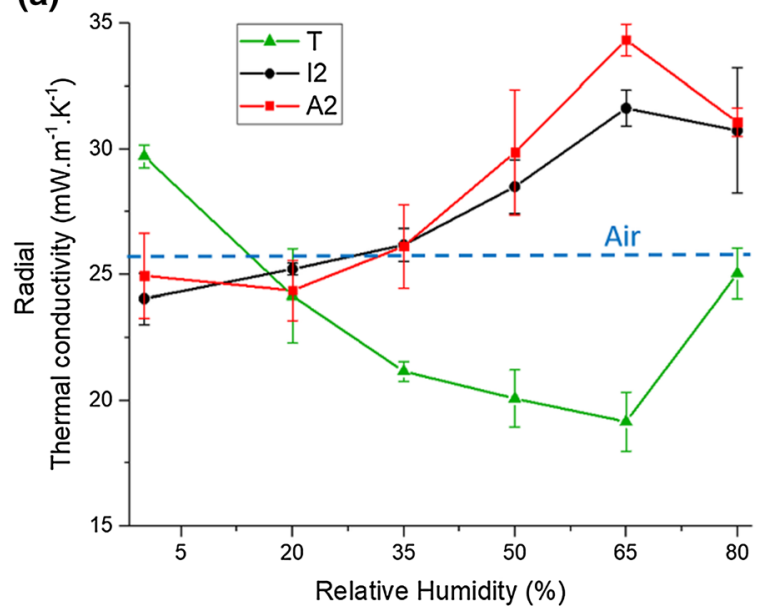

Fig. 4 Thermal conductivity of freeze-cast foams as a function of RH. a The radial thermal conductivity of freeze-cast foams as a function of RH. The thermal conductivity of air

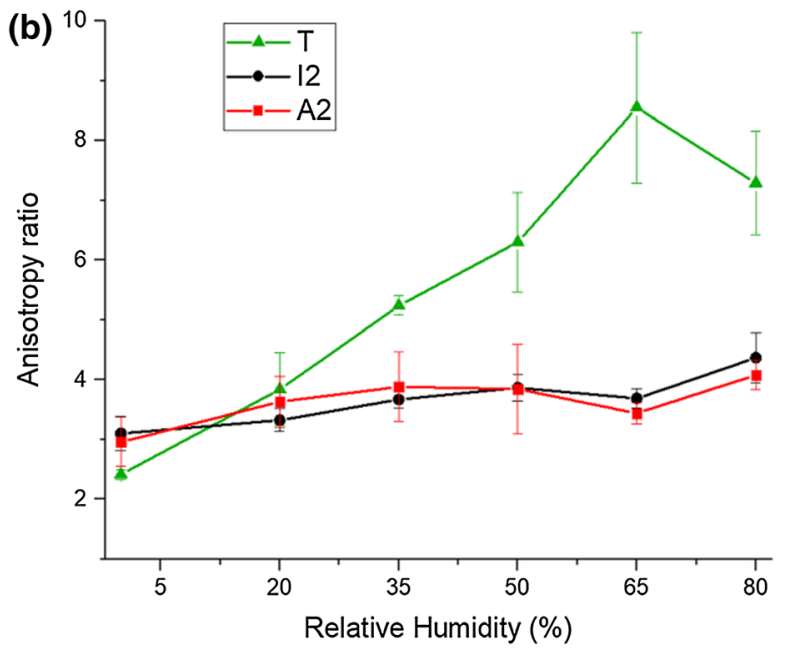

( $25.7 \mathrm{~mW} \mathrm{~m}^{-1} \mathrm{~K}^{-1}$ ) is indicated by a dashed blue line. $\mathbf{b}$ The anisotropy ratio (axial thermal conductivity divided by radial thermal conductivity) of freeze-cast foams as a function of $\mathrm{RH}$

Table 4 Estimated fractions of mesopores and macropores in the foams and their contributions to the gaseous conduction

\begin{tabular}{lllcl}
\hline Sample & $\begin{array}{l}\lambda \mathrm{g} \text { [mesopores] } \\
\left(\mathrm{mW} \mathrm{m}^{-1} \mathrm{~K}^{-1}\right)\end{array}$ & $\begin{array}{l}\lambda \mathrm{g} \text { [macropores] } \\
\left(\mathrm{mW} \mathrm{m}^{-1} \mathrm{~K}^{-1}\right)\end{array}$ & $\begin{array}{l}\text { Fraction of mesopores } \\
(\%)\end{array}$ & $\begin{array}{l}\text { Fraction of macropores } \\
(\%)\end{array}$ \\
\hline $\mathrm{T}$ & 0.1 & 24.5 & 3.85 & 95.84 \\
$\mathrm{I} 2$ & 0.7 & 21.4 & 15.50 & 83.53 \\
$\mathrm{~A} 2$ & 1.4 & 19.5 & 22.76 & 76.32 \\
\hline
\end{tabular}

lower compared to the $\mathrm{T}$ foams (values ranging between 84 and $197 \mathrm{~mW} \mathrm{~m}^{-1} \mathrm{~K}^{-1}$ ). The increase in thermal conductivity with increasing $\mathrm{RH}$ was clearly reduced by the presence of silica particles; the increase in thermal conductivity from 0 to $80 \%$ RH was $133 \%$ for the T foams, $64 \%$ for the I 2 foams and only $54 \%$ for the A2 foams. Interestingly, the axial thermal conductivity increase was the lowest for the A2 foams although the water uptake at $\mathrm{RH}=80 \%$ was almost as high for the $\mathrm{A} 2$ and $\mathrm{T}$ foams, and much lower for the I2 foams (see Table 3).

A more direct way of visualizing the anisotropy in the thermal conductivity of freeze-cast foams is proposed in Fig. 4b, where the ratio between axial and radial thermal conductivity, herein called anisotropy ratio, was plotted against $\mathrm{RH}$. The anisotropy ratio of the $\mathrm{T}$ foams increased strongly with increasing $\mathrm{RH}$ while the anisotropy ratio for composite foams remained almost constant at all $\mathrm{RH}$ (between 3.3 and 4.4 for I 2 and between 3.4 and 4.1 for A2). The radial thermal conductivity was below the value of air at
$\mathrm{RH}<35 \%$ and remained lower than widely used insulation materials at $\mathrm{RH}<80 \%$.

\section{Conclusions}

We have shown that industrially produced silica particles can be processed together with TOCNF to yield mechanically strong silica-TOCNF freeze-cast foams without the addition of surfactants or dispersants. The composite foams displayed columnar porous structures and the organic and inorganic particles were homogeneously distributed in the foam walls. Foams with a silica-TOCNF weight ratio of 2 displayed a high toughness (about 3.5-fold higher compared to $\mathrm{T}$ foams), while maintaining a reasonably low density (around $20 \mathrm{~kg} \mathrm{~m}^{-3}$ ). Interestingly, the addition of anisotropic silica particles enhanced the mechanical strength of the composite foams much more efficiently than isotropic particles, possibly 
because the anisotropic particles could align during freeze-casting.

The thermal conductivity of the composite foams was less affected by RH compared to the TOCNF-only foams. The thermal conductivity in the radial direction at low RH was actually lower than for TOCNF-only foams, with values comparable to that of air, which was attributed to the increased mesoporosity induced by the addition of silica. The radial thermal conductivity of composite foams remained lower than 35 $\mathrm{mW} \mathrm{m} \mathrm{m}^{-1} \mathrm{~K}^{-1}$ up to $\mathrm{RH} 80 \%$. In the axial direction, the increase in thermal conductivity of the composite foams with increasing RH was significantly diminished compared to TOCNF-only foams.

Acknowledgments Open access funding provided by Stockholm University. The Marie Sklodowska-Curie Actions Innovative Training Networks (H2020-MSCA-ITN-2014) and the Swedish Energy Agency (Energimyndigheten) are acknowledged for financial support. The staff of Nouryon Performance Chemicals is thanked for practical support and fruitful discussions, in particular Leif Karlson, Magnus Palmlöf, Fredrik Andersson, Lu Sun and Remco Fijneman. The authors would also like to thank Kjell Jansson and Ehsan Hadi for their assistance with scanning electron microscopy, Anumol Ashok and Konstantin Kriechbaum for their support with transmission electron microscopy and mechanical testing, respectively.

Open Access This article is licensed under a Creative Commons Attribution 4.0 International License, which permits use, sharing, adaptation, distribution and reproduction in any medium or format, as long as you give appropriate credit to the original author(s) and the source, provide a link to the Creative Commons licence, and indicate if changes were made. The images or other third party material in this article are included in the article's Creative Commons licence, unless indicated otherwise in a credit line to the material. If material is not included in the article's Creative Commons licence and your intended use is not permitted by statutory regulation or exceeds the permitted use, you will need to obtain permission directly from the copyright holder. To view a copy of this licence, visit http://creativecommons.org/licenses/by/4.0/.

\section{References}

Apostolopoulou-Kalkavoura V, Gordeyeva K, Lavoine N, Bergström L (2018) Thermal conductivity of hygroscopic foams based on cellulose nanofibrils and a nonionic polyoxamer. Cellulose 25:1117-1126. https://doi.org/10.1007/ s10570-017-1633-y

Baisheng N, Xianfeng L, Longlong Y et al (2015) Pore structure characterization of different rank coals using gas adsorption and scanning electron microscopy. Fuel 158:908-917. https://doi.org/10.1016/j.fuel.2015.06.050
Bouville F, Maire E, Deville S (2014) Self-assembly of faceted particles triggered by a moving ice front. Langmuir 30:8656-8663. https://doi.org/10.1021/la404426d

Chu G, Qu D, Zussman E, Xu Y (2017) Ice-assisted assembly of liquid crystalline cellulose nanocrystals for preparing anisotropic aerogels with ordered structures. Chem Mater 29:3980-3988. https://doi.org/10.1021/acs.chemmater. $7 \mathrm{~b} 00361$

Deville S (2018) The lure of ice-templating: recent trends and opportunities for porous materials. Scr Mater 147:119-124. https://doi.org/10.1016/j.scriptamat.2017. 06.020

Deville S (2010) Freeze-casting of porous biomaterials: structure, properties and opportunities. Materials (Basel) 3:1913-1927. https://doi.org/10.3390/ma3031913

Donius AE, Liu A, Berglund LA, Wegst UGK (2014) Superior mechanical performance of highly porous, anisotropic nanocellulose-montmorillonite aerogels prepared by freeze casting. J Mech Behav Biomed Mater 37:88-99. https:// doi.org/10.1016/j.jmbbm.2014.05.012

Dri FL, Shang S, Hector LG et al (2014) Anisotropy and temperature dependence of structural, thermodynamic, and elastic properties of crystalline cellulose I: a first-principles investigation Anisotropy and temperature dependence of structural, thermodynamic, and elastic properties of crys. Model Simul Mater Sci Eng 22:085012. https://doi.org/10. 1088/0965-0393/22/8/085012

Gelb LD, Gubbinst KE (1998) Characterization of porous glasses: simulation models, adsorption isotherms, and the Brunauer-Emmett-Teller analysis method. Langmuir 14:2097-2111. https://doi.org/10.1021/la9710379

Gibson LJ, Ashby MF (1999) The mechanics of honeycombs. In: Cellular solids: structure and properties. Cambridge University Press, Cambridge, pp 93-174

Glicksman LR (1994) Heat transfer in foams. In: Hilyard NC (ed) Low density cellular plastics. Springer, Dordrecht, pp 104-152

Gordeyeva KS, Fall AB, Hall S et al (2016) Stabilizing nanocellulose-nonionic surfactant composite foams by delayed Ca-induced gelation. J Colloid Interface Sci 472:44-51. https://doi.org/10.1016/j.jcis.2016.03.031

Groult S, Budtova T (2018) Thermal conductivity/structure correlations in thermal super-insulating pectin aerogels. Carbohydr Polym 196:73-81. https://doi.org/10.1016/j. carbpol.2018.05.026

Guo L, Chen Z, Lyu S et al (2018a) Highly flexible cross-linked cellulose nanofibril sponge-like aerogels with improved mechanical property and enhanced flame retardancy. Carbohydr Polym 179:333-340. https://doi.org/10.1016/j. carbopol.2017.09.084

Guo W, Wang X, Zhang P et al (2018b) Nano-fibrillated cellulose-hydroxyapatite based composite foams with excellent fire resistance. Carbohydr Polym 195:71-78. https:// doi.org/10.1016/j.carbpol.2018.04.063

Gustafsson SE (1991) Transient plane source techniques for thermal conductivity and thermal diffusivity measurements of solid materials. Rev Sci Instrum 62:797. https:// doi.org/10.1063/1.1142087

Horvath JS (1994) Expanded polystyrene (EPS) geofoam: an introduction to material behavior. Geotext Geomembranes 13:263-280. https://doi.org/10.1016/0266-1144(94)90048_5 
Hunger PM, Donius AE, Wegst UGK (2013) Platelets selfassemble into porous nacre during freeze casting. $\mathrm{J}$ Mech Behav Biomed Mater 19:87-93. https://doi.org/10.1016/j. jmbbm.2012.10.013

Illera D, Mesa J, Gomez H, Maury H (2018) Cellulose Aerogels for thermal insulation in buildings: trends and challenges. Coatings. https://doi.org/10.3390/coatings 8100345

ISO/TS 20477 (2017) International Organization for standardization. Nanotechnologies-standard terms and their definition for cellulose. ISO/TS 204:2017, Geneva

Jelle BP (2011) Traditional, state-of-the-art and future thermal building insulation materials and solutions-properties, requirements and possibilities. Energy Build 43:2549-2563. https://doi.org/10.1016/j.enbuild.2011.05. 015

Kontturi E, Laaksonen P, Linder MB et al (2018) Advanced materials through assembly of nanocelluloses. Adv Mater 30:1703779. https://doi.org/10.1002/adma.201703779

Korhonen JT, Kettunen M, Ras RHA, Ikkala O (2011) Hydrophobic nanocellulose aerogels as floating, sustainable, reusable, and recyclable oil absorbents. ACS Appl Mater Interfaces 3:1813-1816. https://doi.org/10.1021/ am200475b

Kriechbaum K, Munier P, Apostolopoulou-Kalkavoura V, Lavoine N (2018) Analysis of the porous architecture and properties of anisotropic nanocellulose foams-a novel approach to assess the quality of cellulose nanofibrils (CNFs). ACS Sustain Chem Eng 6:11959-11967. https:// doi.org/10.1021/acssuschemeng.8b02278

Lavoine N, Bergström L (2017) Nanocellulose-based foams and aerogels: processing, properties, and applications. J Mater Chem A 5:16105. https://doi.org/10.1039/c7ta02807e

Munier P, Gordeyeva K, Bergström L, Fall AB (2016) Directional freezing of nanocellulose dispersions aligns the rodlike particles and produces low-density and robust particle networks. Biomacromol 17:1875-1881. https://doi.org/10. 1021/acs.biomac.6b00304

Nguyen ST, Feng J, Ng SK et al (2014) Advanced thermal insulation and absorption properties of recycled cellulose aerogels. Colloids Surf A Physicochem Eng ASP 445:128-134. https://doi.org/10.1016/j.colsurfa.2014.01. 015

Ocklind A (2016) A. Humidifier P-series. Cellkraft 1-3. https:// www.cellkraft.se/downloads/P-Series.pdf

Ojuva A, Akhtar F, Tomsia AP, Bergström L (2013) Laminated adsorbents with very rapid $\mathrm{CO}_{2}$ uptake by freeze-casting of zeolites. ACS Appl Mater Interfaces 5:2669-2676. https:// doi.org/10.1021/am400122r

Park M, Lee D, Shin S, Hyun J (2015) Effect of negatively charged cellulose nanofibers on the dispersion of hydroxyapatite nanoparticles for scaffolds in bone tissue engineering. Colloids Surf B Biointerfaces 130:222-228. https://doi.org/10.1016/j.colsurfb.2015.04.014

Rajinipriya M, Nagalakshmaiah M, Robert M, Elkoun S (2018) Importance of agricultural and industrial waste in the field of nanocellulose and recent industrial developments of wood based nanocellulose: a review. ACS Sustain Chem Eng 6:2807-2828. https://doi.org/10.1021/acssuschemeng. $7 \mathrm{~b} 03437$
Saito T, Isogai A (2004) TEMPO-mediated oxidation of native cellulose. The effect of oxidation conditions on chemical and crystal structures of the water-insoluble fractions. Biomacromol 5:1983-1989. https://doi.org/10.1021/ bm0497769

Saito T, Kimura S, Nishiyama Y, Isogai A (2007) Cellulose nanofibers prepared by tempo-mediated oxidation of native cellulose. Biomacromol 8:2485-2491. https://doi.org/10. 1021/bm0703970

Sehaqui H, Zhou Q, Berglund LA (2011) High-porosity aerogels of high specific surface area prepared from nanofibrillated cellulose (NFC). Compos Sci Technol 71:1593-1599. https://doi.org/10.1016/j.compscitech.2011.07.003

Sehaqui H, Ezekiel Mushi N, Morimune S et al (2012) Cellulose nanofiber orientation in nanopaper and nanocomposites by cold drawing. ACS Appl Mater Interfaces 4:1043-1049. https://doi.org/10.1021/am2016766

Tripathi A, Tardy BL, Khan S et al (2019) Expanding the upper limits of robustness for cellulose nanocrystal aerogels: outstanding mechanical performance and associated pore compression of chiral-nematic architectures. J Mater Chem A 7:15309-15319. https://doi.org/10.1039/C9TA03950C

Wegst UGK, Schecter M, Donius AE, Hunger PM (2010) Biomaterials by freeze casting. Philos Trans R Soc A Math Phys Eng Sci 368:2099-2121. https://doi.org/10.1098/rsta. 2010.0014

Wicklein B, Kocjan A, Salazar-Alvarez G et al (2014) Thermally insulating and fire-retardant lightweight anisotropic foams based on nanocellulose and graphene oxide. Nat Nanotechnol. https://doi.org/10.1038/nnano.2014.248

Zeng SQ, Hunt A, Greif R (1995) Transport properties of gas in silica aerogel. J Non Cryst Solids 186:264-270. https://doi. org/10.1016/0022-3093(95)00052-6

Zhao S, Malfait WJ, Demilecamps A et al (2015a) Strong, thermally superinsulating biopolymer-silica aerogel hybrids by cogelation of silicic acid with pectin. Angew Chemie Int Ed 54:14282-14286. https://doi.org/10.1002/ anie. 201507328

Zhao S, Zhang Z, Sèbe G et al (2015b) Multiscale assembly of superinsulating silica aerogels within silylated nanocellulosic scaffolds: improved mechanical properties promoted by nanoscale chemical compatibilization. Adv Funct Mater 25:2326-2334. https://doi.org/10.1002/adfm.201404368

Zhao S, Malfait WJ, Guerrero Alburquerque N et al (2018) Biopolymer aerogels: chemistry, properties and applications. Angew Chemie Int Ed. https://doi.org/10.1002/anie. 201709014

Zhu H, Yang X, Cranston ED, Zhu S (2016) Flexible and porous nanocellulose aerogels with high loadings of metal-organic-framework particles for separations applications. Adv Mater 28:7652-7657. https://doi.org/10.1002/adma. 201601351

Zuo K, Wu J, Chen S et al (2019) Superamphiphobic nanocellulose aerogels loaded with silica nanoparticles. Cellulose 6:1-11. https://doi.org/10.1007/s10570-019-02774-6

Publisher's Note Springer Nature remains neutral with regard to jurisdictional claims in published maps and institutional affiliations. 